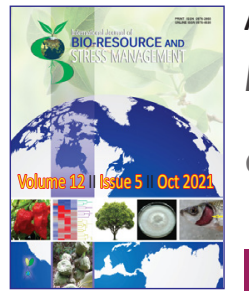

\title{
Exploitation of Heterosis for Seed Yield and its Contributing Traits in CMS Based Hybrids of Indian Mustard [Brassica juncea (L.) Czern and Coss]
}

\author{
D. A. Patel ${ }^{1}$, D. K. Patel ${ }^{2}$, J. R. Pate $\left.\right|^{3 *}$, K. P. Prajapati ${ }^{3}$, P. J. Patel ${ }^{4}$ and A. B. Patel ${ }^{1}$
}

${ }^{1}$ Dept. of Genetics and Plant Breeding, C. P. College of Agriculture, Sardarkrushinagar Dantiwada Agricultural University, Sardarkrushinagar , Gujarat (385 506), India

${ }^{2}$ Dept. of Seed Technology, Sardarkrushinagar Dantiwada Agricultural University, Sardarkrushinagar, Gujarat (385 506), India ${ }^{3}$ Castor-Mustard Research Station, Sardarkrushinagar Dantiwada Agricultural University, Sardarkrushinagar, Gujarat (385506), India

${ }^{4}$ Seed Spices Research Station, Sardarkrushinagar Dantiwada Agricultural University, Jagudan, Gujarat (382 710), India

Open Access

Corresponding Author

J. R. Patel

e-mail: pateljignesh212@gmail.com

Citation: Patel et al., 2021. Exploitation of Heterosis for Seed Yield and its Contributing Traits in CMS Based Hybrids of Indian Mustard [Brassica juncea (L.) Czern and Coss]. International Journal of Bio-resource and Stress Management 2021, 12(5), 552-563. HTTPS:// DOI.ORG/10.23910/1.2021.2354.

Copyright: (c) 2021 Patel et al. This is an open access article that permits unrestricted use, distribution and reproduction in any medium after the author(s) and source are credited.

Data Availability Statement: Legal restrictions are imposed on the public sharing of raw data. However, authors have full right to transfer or share the data in raw form upon request subject to either meeting the conditions of the original consents and the original research study. Further, access of data needs to meet whether the user complies with the ethical and legal obligations as data controllers to allow for secondary use of the data outside of the original study.

Conflict of interests: The authors have declared that no conflict of interest exists.

\begin{abstract}
In the present study, linex tester analysis was carried out at Castor-Mustard Research Station, S. D. Agricultural University, Sardarkrushinagar, Gujarat, India during rabi 2018-19 (October 2018 to February 2019) in order to estimate all three types of heterosis (relative heterosis, heterobeltiosis and economic heterosis) for identification of superior cross combinations of Indian mustard [Brassica juncea (L.) Czern\&Coss]. Thirty-five hybrids along with five CMS lines, seven testers and check GDM 4 were evaluated for ten different traits. The $F_{1}$ generation of all the crosses exhibited fertility restoration with pollen fertility except $F_{1}$ crosses with Vardan, Rohini and SKM 319 fertile line (0\%). The remaining crosses exhibited pollen fertility ranging from $68.26 \%$ (Kranti×SKM 303) to $85.17 \%$ (KrantixMori ' $R$ ' 1-18). The analysis of variance for parents, hybrids and parents vs. hybrids revealed that mean sum of squares of parents were highly significant for majority of the characters except days to maturity. Whereas, hybrids differed highly significant for all the characters. Comparison of mean squares due to parents vs. hybrids was found significant for almost all the characters except number of seeds siliqua ${ }^{-1}$ and oil content. This indicates that considerable amount of genetic variability present among the parents and hybrids for all the characters studied. On the basis of per se performance, three hybrids viz., KrantixMori ' $R$ ' 1-18, SKM

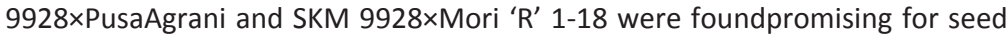
yield plant ${ }^{-1}$ over the standard check GDM 4 . With respect to heterosis, one of the hybrid KrantixMori ' $\mathrm{R}^{\prime}$ 1-18 (17.85\%)manifested significant and positive standard heterosis for seed yield plant ${ }^{-1}$.
\end{abstract}

Keywords: Heterosis and Mori CMS, Indian mustard

\section{Introduction}

Indian mustard (Brassica juncea L.) is an important rabi season (October to March) oilseed crop in India which is popularly known as rai, raya or laha. The genus Brassica, belongs to brassicaceae family. Indian mustard is a natural amphidiploid $(2 n=36)$ of Brassica campestris $(2 n=20)$ and Brassica nigra $(2 n=16)$ (Nagaharu, 1935). Brassica juncea is a crop of Asiatic origin with its major centre of diversity in China from where it was introduced in India (Vaughan, 1977). It is the second important oilseed crop at national level and contributes nearly $27 \%$ of edible oil pool of the country (Singh et al., 2013). It is a naturally autogamous species

Article History

RECEIVED on $12^{\text {th }}$ May 2021 RECEIVED in revised form on $13^{\text {th }}$ September 2021 ACCEPTED in final form on $25^{\text {th }} 0$ Cctober 2021 
in which out crossing varies from $5-30 \%$ depending upon environmental conditions and frequency of pollinating insects (Shrimali et al., 2016). Mustard seed contains about 38 to $46 \%$ oil.It is mainly grown for oil-seed usage in India. In Northern India, mustard oil is mainly utilized for human consumption (Vaghela et al., 2011). Mustard oil has isothiocyanates as the most important content contained responsible for its flavour and pungency (Park et al., 2018). In addition to its use as edible oil, mustard oil has a spectrum of industrial utilities such as paintand printing ink additives, greases and lubricants, resins and polymers, plastics, cosmetics and also in the pharmaceutical industries (Gupta, 2016). Globally, India is the second largest rapeseed-mustard-cultivating country after China and third in production next to China and Canada (Kumari et al., 2019). It was cultivated in an area of 6.85 million hectares in India with an annual production of 9.12 million tonnes and productivity of $1331 \mathrm{~kg} \mathrm{ha}^{-1}$ (Anonymous, 201920). Major rapeseed-mustard growing states are Rajasthan, Uttar Pradesh, Madhya Pradesh, Punjab, Gujarat, Haryana, Assam, Bihar and West Bengal.

Seed yield a very complex trait, possesses many components which finally result in a highly plastic yield structure (Diepenbrock, 2000). Heterosis has an important role in all the plant breeding programmes; it would be very helpful to know the relationship between heterosis for seed yield and its components (Azizia, 2011). In oilseed Brassicas heterosis was first reported in brown sarson by Singh and Mehta (1954). Subsequently many studies have reported the extent of heterosis for seed yield. Significant level of heterosis was reported in B. juncea (13 to 91\%) by Verma et al. (2011), Yadava et al. (2012) and Meena et al. (2015). Exploitable level of standard heterosis depends on an effective male sterility and fertility system which is the most important prerequisites for the development of commercially viable hybrids. Restoration ability in CMS line is an important factor for the exploitation of hybrid in the breeding programme. Alloplasmic $B$. juncea and $B$. napus have been obtained based on B. oxyrrhina, Trachystomaballi, Moricandia arvensis, Diplotaxissiifoliaand Sinapis alba cytoplasm (Raoand Shivanna., 1996; Prakash et al., 2001). Fertility restorers have been identified in the Trachystoma and Moricandia based CMS lines of $B$. juncea (Prakash and Kirti, 1997). Among the different sterile cytoplasms, Moricandia arvensis (mori) and Diplotaxis erucoides (eru) cytoplasms are proved to be stable and with almost no adverse effects in $B$. juncea backgrounds (Kaur et al., 2004, Chamola et al., 2013). The mori CMS system is available in $B$. juncea with small non-dehiscent anthers and excellent nectarines. Restorers are available and female fertility is about $95 \%$ for this cms system. The mori CMS system was developed by Prakash et al. (1998) and subsequently rectified by Kirti et al. (1998). Alloplasmic lines having cytoplasm from Diplotaxis erucoides (eru) and Diplotaxis berthautii (ber) were developed by Malik et al. (1999) and later improved by Bhat et al. $(2006,2008)$. Heterosis has been extensively explored and utilized for boosting various quality traits in Brassica because of an effective and economic pollination control system for production of $F_{1}$ hybrid seeds on a large scale. With these facts, in the present study, restoration ability and level of standard heterosis were estimated for the hybrids developed using LXT mating design.

\section{Materials and Methods}

\subsection{Plant material and experimental details}

The study was conducted during rabi 2018-19 (October 2018 to February 2019) at Castor-Mustard Research Station, Sardarkrushinagar Dantiwada Agricultural University, Sardarkrushinagar, Gujarat, India. Sardarkrushinagar is situated at semi-arid region of North Gujarat. Geographically, it is situated at $24^{\circ} .31^{\prime} \mathrm{N}$ latitude and $72^{\circ} .32^{\prime} \mathrm{E}$ longitude with an altitude of 154.52 meters above the mean sea level. The experimental material for the present study includes five Mori based CMS lines (SKM 301, SKM 9928, GM 1, Kranti and GM 2) as female parent and seven Mori based restorer lines (Vardan, Rohini, SKM 319, SKM 303, Pusa Agrani, PCR 7 and Mori 'R' 1-18) as male parent to generate 35 alloplasmichybrids.At the same time, male sterile lines (A lines) werecrossed with its maintainer lines ( $B$ line) to get seeds of female parents for evaluationin the next season and the testers or restorer lines (male parents) were selfed to getpure seeds. Female line is CMS, so hand emasculation is not necessary While hybridization was carried out by manual hand pollination. During rabi 2018-19, a set of 48 genotypes comprising of twelve parents and their $35 \mathrm{~F}_{1}$ hybrids along with standard check GDM 4 were sown in Randomized Complete Block Design with three replications. The soil of the experimental field was sandy loam with $\mathrm{pH}$ 7.5. Each entry was sown in 3 $\mathrm{m}$ row length with $45 \times 15 \mathrm{~cm}^{2}$ spacing. The recommended agronomical practices and plant protection measures were adopted to raise healthy crop.

\subsection{Assessment of pollen fertility in $F_{1}$ generation}

In the field, pollen fertility was tested as number of siliquae set on selfing per bag and \% siliquae set on selfing. In the laboratory, pollen fertility/sterility of $F_{1}$ crosses was tested with $2 \%$ acetocarmine. All the hybrids have been tested for their pollen fertility status (Alexander, 1969) at the initial flowering stage of randomly selected plant. The round and well stained pollen grains were counted as fertile, while shrivelled hyaline pollen grains were scored as sterile. The mean for all the microscopic fields were worked out and the proportions of fertile pollens were expressed in \% for individual plants. Based on the number of stained and unstained pollen grains, the fertility status was computed as follows:

Pollen fertility $(\%)=(($ Number of round and stained pollen (fertile pollen)/Total number of pollen grains examined)) $\times 100$

\subsection{Traits measurement}

The observations were recorded on five randomly selected plants from each replicationfor all the traits viz., plant height 
$(\mathrm{cm})$, total number of branches plant ${ }^{-1}$, total number of siliquae plant ${ }^{-1}$, siliqua length $(\mathrm{cm})$, number of seeds siliqua ${ }^{-1}$, seed yield plant ${ }^{-1}(\mathrm{~g}), 1000$ seed weight ( $\mathrm{g}$ ) and oil content (\%) except days to flowering and days to maturity which were recorded on plot basis. The oil content of each samples was estimated in \% by using Nuclear Magnetic Resonance (NMR) Technique (Tiwari et al., 1974).

\subsection{Statistical analysis}

The analysis of variance was carried out for ten characters as per the procedure described by Panse and Sukhatame (1967). The estimate of heterosis was calculated using the procedure of Turner (1953), heterobeltiosis by Fonesca and Patterson (1968) and economic heterosis by Meredith and Bridges (1972).

\section{Results and Discussion}

The present study was conducted using five cytoplasmic male sterile (CMS) lines and seven diverse male fertile lines to generate $35 \mathrm{~F}_{1}$ hybrids in Indian mustard. For the experimental materials, selfing of one inflorescence of each $F_{1}$ plant was also carried out to examine ability or inability of the plant to produce selfed seeds for field confirmation. The pollen fertility was observed for all the $F_{1}$ crosses and standard check GDM 4 (Figure 1 and Figure 2) under light microscope and on the basis of its staining properties, pollen grains which were round, deep to light red colour consider as fertile pollen and shrivelled, hyaline, transparent or light yellow colour consider as sterile pollen. There were visual differences observed in all the $F_{1}$ crosses and standard check for the pollen fertility which are presented in Table 1.

The crosses made by CMS lines and male fertile lines SKM 303, Pusa Agrani, PCR 7 and Mori ' $R$ ' 1-18 exhibited pollen fertility which ranged from $68.26 \%$ to $85.17 \%$, whereas standard check GDM 4 had $91.36 \%$ pollen fertility, while the crosses carried out by crossing CMS lines and male fertile lines Vardan, Rohini and SKM 319 had 0\% pollen fertility, i.e., totally sterile pollen (Table 1). These results were further confirmed by ability to produce seed set upon self-fertilization. The crosses made by CMS lines and male fertile lines SKM 303, PusaAgrani, PCR 7 and Mori ' $R$ ' 1-18 exhibited \% siliquae set by selfpollination, which was ranging from $66.99 \%$ to $83.82 \%$, where as standard check GDM 4 had $89.76 \%$ siliquae set, while the crosses carried out by crossing CMS lines and male fertile lines Vardan, Rohini and SKM 319 had 0\% siliquae set (Table 2). It

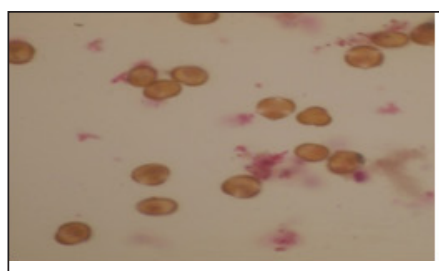

SKM 301×Vardan

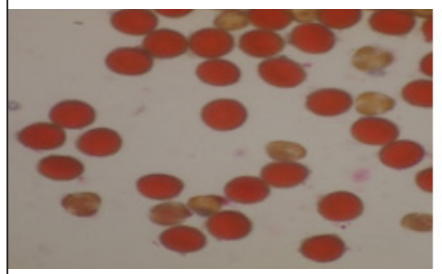

SKM 9928×Pusa Agrani

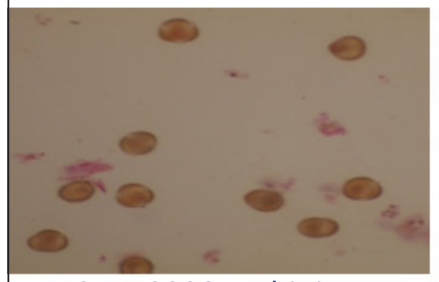

SKM 9928×Rohini

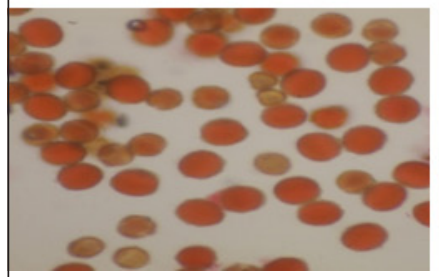

SKM 9928×PCR 7

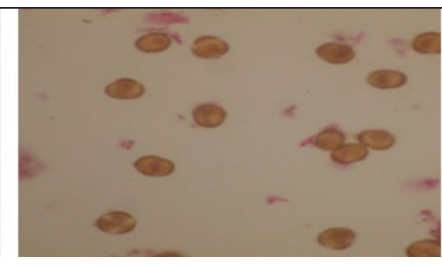

SKM 301×Rohini

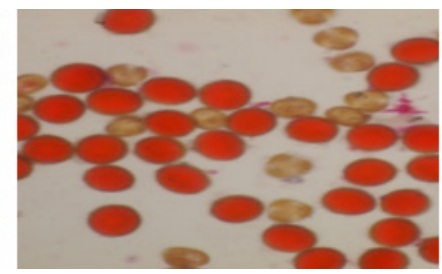

SKM 301×PCR 7

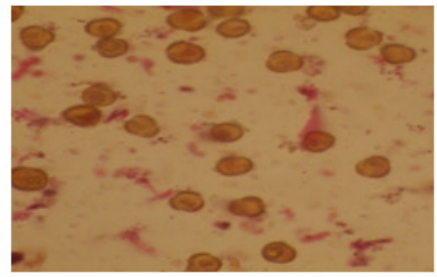

SKM 9928×SKM 319

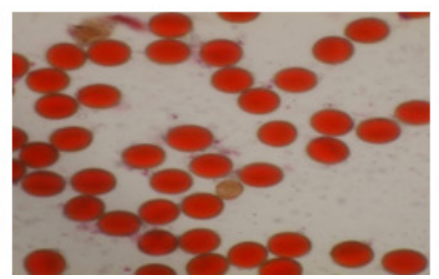

SKM 9928×Mori 'R' 1-18

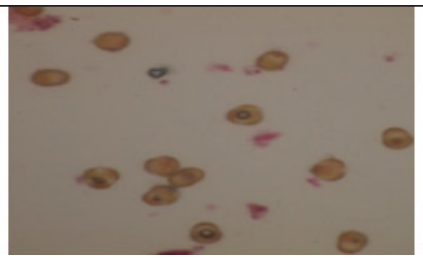

SKM 301×SKM 319

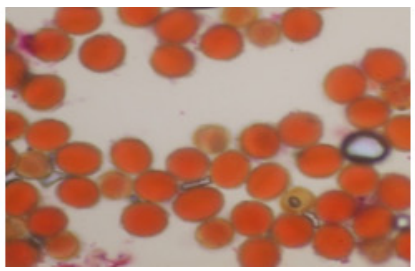

SKM 301×Mori 'R' 1-18

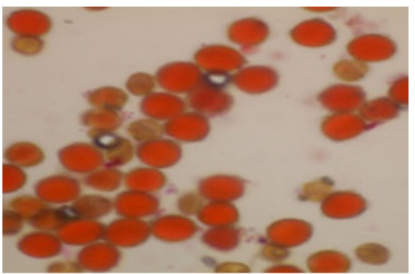

SKM 9928×SKM 303

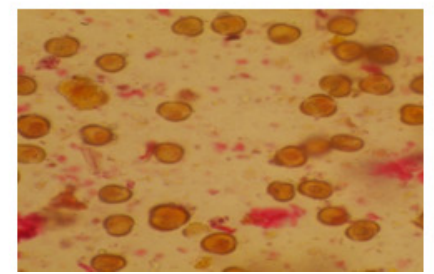

GM 1×Vardan

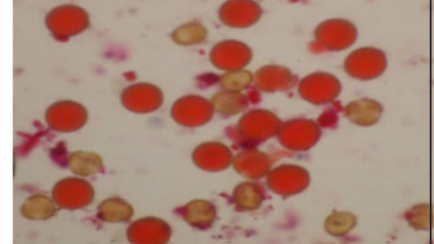

SKM 301×SKM 303

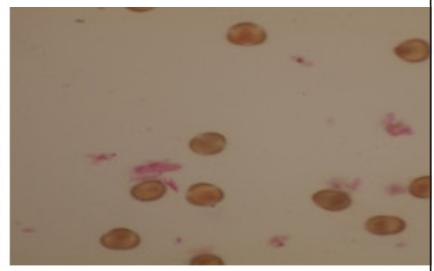

SKM 9928×Vardan

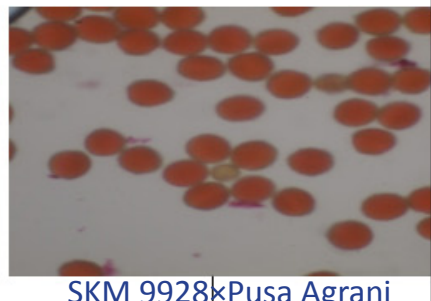

SKM 9928xPusa Agrani

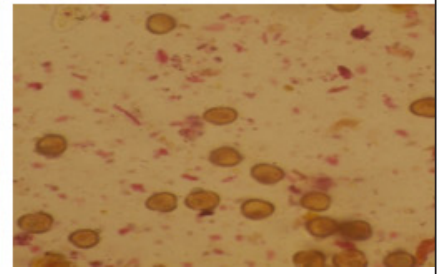

GM 1×Rohini

Figure 1: Pollen grain stainability of hybrids 


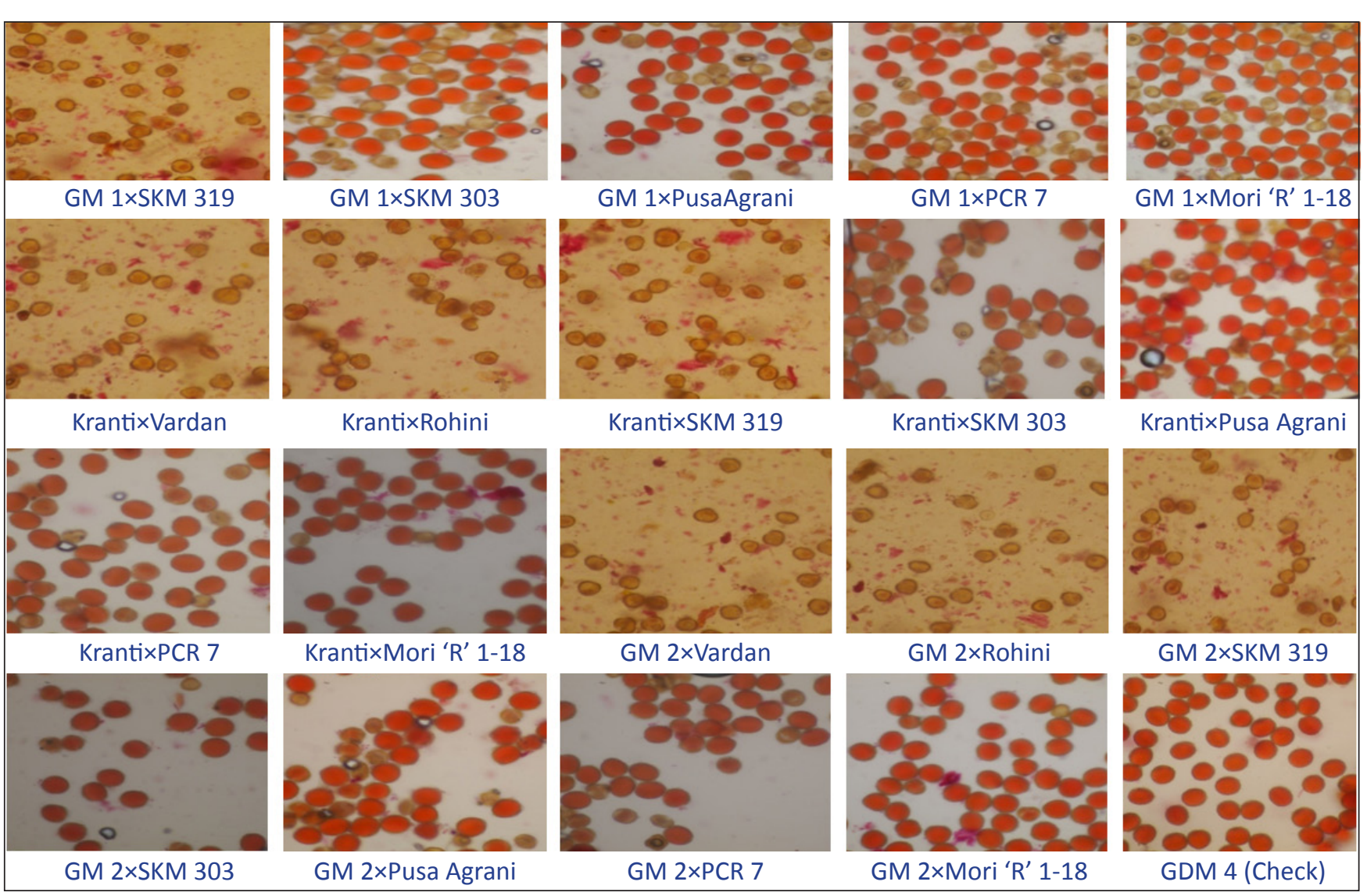

Figure 2: Pollen grain stainability of hybrids

Table 1: Pollen fertility status of $F_{1}$ hybrids and standard check (GDM 4) in Indian mustard

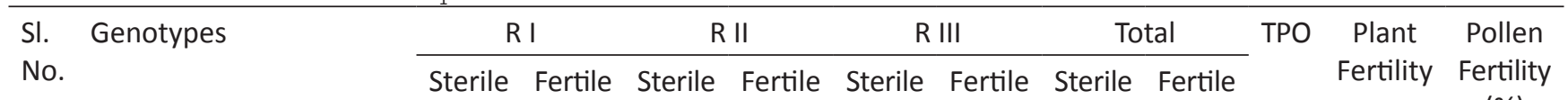

\begin{tabular}{|c|c|c|c|c|c|c|c|c|c|c|c|c|}
\hline 1. & SKM 301×Vardan & 46 & 0 & 58 & 0 & 53 & 0 & 157 & 0 & 157 & $\mathrm{~S}$ & 0 \\
\hline 2. & SKM 301×Rohini & 54 & 0 & 38 & 0 & 39 & 0 & 131 & 0 & 131 & $\mathrm{~S}$ & 0 \\
\hline 3. & SKM 301×SKM 319 & 33 & 0 & 42 & 0 & 46 & 0 & 121 & 0 & 121 & $\mathrm{~S}$ & 0 \\
\hline 4. & SKM 301×SKM 303 & 23 & 57 & 19 & 52 & 21 & 55 & 63 & 164 & 227 & $\mathrm{~F}$ & 72.24 \\
\hline 5. & SKM 301×Pusa Agrani & 10 & 33 & 15 & 46 & 18 & 55 & 43 & 134 & 177 & $\mathrm{~F}$ & 75.70 \\
\hline 6. & SKM 301×PCR 7 & 12 & 34 & 22 & 56 & 21 & 62 & 55 & 152 & 207 & $\mathrm{~F}$ & 73.42 \\
\hline 7. & SKM 301×Mori 'R' 1-18 & 19 & 60 & 20 & 68 & 22 & 72 & 61 & 200 & 261 & $\mathrm{~F}$ & 76.62 \\
\hline 8. & SKM 9928×Vardan & 51 & 0 & 56 & 0 & 44 & 0 & 151 & 0 & 151 & $\mathrm{~S}$ & 0 \\
\hline 9. & SKM 9928×Rohini & 40 & 0 & 52 & 0 & 62 & 0 & 154 & 0 & 154 & $\mathrm{~S}$ & 0 \\
\hline 10. & SKM 9928×SKM 319 & 45 & 0 & 48 & 0 & 59 & 0 & 152 & 0 & 152 & $\mathrm{~S}$ & 0 \\
\hline 11. & SKM 9928×SKM 303 & 24 & 57 & 31 & 72 & 20 & 48 & 75 & 177 & 252 & $\mathrm{~F}$ & 70.23 \\
\hline 12. & SKM 9928×Pusa Agrani & 19 & 53 & 18 & 54 & 22 & 65 & 59 & 172 & 231 & $\mathrm{~F}$ & 74.45 \\
\hline 13. & SKM 9928×PCR 7 & 20 & 49 & 26 & 62 & 26 & 69 & 72 & 180 & 252 & $\mathrm{~F}$ & 71.42 \\
\hline 14. & SKM 9928×Mori ‘R’ 1-18 & 14 & 64 & 21 & 78 & 13 & 71 & 48 & 213 & 261 & $\mathrm{~F}$ & 81.61 \\
\hline 15. & GM 1×Vardan & 53 & 0 & 56 & 0 & 48 & 0 & 157 & 0 & 157 & $\mathrm{~S}$ & 0 \\
\hline 16. & GM 1×Rohini & 48 & 0 & 64 & 0 & 58 & 0 & 170 & 0 & 170 & $\mathrm{~S}$ & 0 \\
\hline
\end{tabular}




\begin{tabular}{|c|c|c|c|c|c|c|c|c|c|c|c|c|}
\hline \multirow{2}{*}{$\begin{array}{l}\text { Sl. } \\
\text { No. }\end{array}$} & \multirow[t]{2}{*}{ Genotypes } & \multicolumn{2}{|c|}{ RI } & \multicolumn{2}{|c|}{$\mathrm{R} \| \mathrm{I}$} & \multicolumn{2}{|c|}{ R III } & \multicolumn{2}{|c|}{ Total } & \multirow[t]{2}{*}{ TPO } & \multirow{2}{*}{$\begin{array}{l}\text { Plant } \\
\text { Fertility }\end{array}$} & \multirow{2}{*}{$\begin{array}{c}\text { Pollen } \\
\text { Fertility } \\
(\%)\end{array}$} \\
\hline & & Sterile & Fertile & Sterile & Fertile & Sterile & Fertile & Sterile & Fertile & & & \\
\hline 17. & GM 1×SKM 319 & 59 & 0 & 52 & 0 & 48 & 0 & 159 & 0 & 159 & $\mathrm{~S}$ & 0 \\
\hline 18. & GM 1×SKM 303 & 28 & 66 & 20 & 42 & 24 & 56 & 72 & 164 & 236 & $\mathrm{~F}$ & 69.49 \\
\hline 19. & GM 1×Pusa Agrani & 17 & 43 & 19 & 52 & 22 & 64 & 58 & 159 & 217 & $\mathrm{~F}$ & 73.27 \\
\hline 20. & GM 1×PCR 7 & 28 & 74 & 29 & 65 & 24 & 58 & 81 & 197 & 278 & $\mathrm{~F}$ & 70.86 \\
\hline 21. & GM 1×Mori ‘R’ 1-18 & 24 & 69 & 22 & 64 & 24 & 62 & 70 & 195 & 265 & $\mathrm{~F}$ & 73.58 \\
\hline 22. & KrantixVardan & 48 & 0 & 61 & 0 & 64 & 0 & 173 & 0 & 173 & S & 0 \\
\hline 23. & Kranti×Rohini & 47 & 0 & 66 & 0 & 58 & 0 & 171 & 0 & 171 & S & 0 \\
\hline 24. & Kranti×SKM 319 & 54 & 0 & 49 & 0 & 56 & 0 & 159 & 0 & 159 & S & 0 \\
\hline 25. & Kranti×SKM 303 & 16 & 38 & 24 & 48 & 26 & 56 & 66 & 142 & 208 & $\mathrm{~F}$ & 68.26 \\
\hline 26. & KrantixPusaAgrani & 34 & 76 & 26 & 66 & 22 & 62 & 82 & 204 & 286 & $\mathrm{~F}$ & 71.32 \\
\hline 27. & KrantixPCR 7 & 16 & 49 & 22 & 56 & 18 & 54 & 56 & 159 & 215 & $\mathrm{~F}$ & 73.95 \\
\hline 28. & Kranti×Mori ‘R’ 1-18 & 16 & 76 & 10 & 70 & 13 & 78 & 39 & 224 & 263 & $\mathrm{~F}$ & 85.17 \\
\hline 29. & GM 2×Vardan & 45 & 0 & 64 & 0 & 58 & 0 & 167 & 0 & 167 & S & 0 \\
\hline 30. & GM 2×Rohini & 51 & 0 & 68 & 0 & 62 & 0 & 181 & 0 & 181 & S & 0 \\
\hline 31. & GM 2×SKM 319 & 59 & 0 & 62 & 0 & 66 & 0 & 187 & 0 & 187 & S & 0 \\
\hline 32. & GM 2×SKM 303 & 26 & 55 & 25 & 66 & 19 & 48 & 70 & 169 & 239 & $\mathrm{~F}$ & 70.71 \\
\hline 33. & GM 2×Pusa Agrani & 14 & 38 & 18 & 46 & 21 & 54 & 53 & 138 & 191 & $\mathrm{~F}$ & 72.25 \\
\hline 34. & GM 2×PCR 7 & 13 & 35 & 18 & 48 & 22 & 58 & 53 & 141 & 194 & $\mathrm{~F}$ & 72.68 \\
\hline 35. & GM 2×Mori ‘R’ 1-18 & 19 & 69 & 14 & 58 & 22 & 72 & 55 & 199 & 254 & $\mathrm{~F}$ & 78.34 \\
\hline 36. & GDM 4 (Standard Check) & 4 & 58 & 6 & 65 & 9 & 78 & 19 & 201 & 220 & $\mathrm{~F}$ & 91.36 \\
\hline
\end{tabular}

$\mathrm{S}:$ Sterile, F : Fertile; TPO: Total pollen observed

suggested that the male fertile line Vardan, Rohini and SKM 319 lacks the fertility restorer gene (Rf) and has no ability to restore fertility upon crossing with cytoplasmic male sterile possessing Moricandia background. The results are supported by Kumar et al. (2014a). The CMS line crossed with pollen fertility restorer line plants $\left(\mathrm{F}_{1}{ }^{\prime} \mathrm{s}\right)$ exhibited in Kranti×SKM 303 (68.26\%) to KrantixMori ' $\mathrm{R}^{\prime}$ 1-18 (85.17\%) and KrantixSKM 303 (66.99\%) to Kranti×Mori ' $R$ ' 1-18 (83.82\%) pollen fertility and $\%$ siliquae set, respectively which subsequently increases in selfed progeny. Similar results were also obtained by Banga et al. (2003).

The aim of estimation of heterosis was to mark the best combination of parents giving high degree of useful heterosis for seed yield and its contributing characters for its future use in the breeding programme. In the present investigation, out ofthirty fivecrosses, fifteen crosses were sterile in both pollen fertility $(0 \%)$ and siliquae set $\%(0 \%)$ study so, these fifteen sterile crosses were not considered for the estimation of heterosis and not discussed onward in heterosis studies. Heterosis was measured as \% increase or decrease of $\mathrm{F}_{1}$ over the mid parental value (relative heterosis), better parent (heterobeltiosis) and over standard check GDM 4 (standard heterosis) for all the characters under study. The analysis of variance for parents, hybrids and parents vs. hybrids revealed that mean sum of squares of parents were highly significant for majority of the characters except days to maturity. Whereas, hybrids differed highly significant for all the characters. Comparison of mean squares due to parents vs. hybrids was found significant for almost all the characters except number of seeds siliqua ${ }^{-1}$ and oil content (Table 3 ). This indicates that considerable amount of genetic variability present among the parents and hybrids for all the characters studied. Similar results were also recorded for all the charactersexcept seed yield plant ${ }^{-1}$ by Synrem et al. (2015), while for all the characters by Chaurasiya et al. (2018).

Overall performance of the hybrids with respect to relative heterosis for yield components revealed that ten hybrids, SKM 9928×SKM 303(63.31\%), SKM 9928×Pusa Agrani (126.29\%), SKM 9928×PCR 7 (75.85\%), SKM 9928×Mori 'R' 1-18 (102.68\%), GM 1×Pusa Agrani (65.54\%), GM 1×PCR 7 (58.01\%), GM 1×Mori ' $R$ ' 1-18 (62.58\%), Kranti×Mori ' $R$ ' 1-18 (34.18\%), GM 2×Pusa Agrani (37.30\%) and GM 2×Mori ' $R$ ' 1-18 (58.84\%) exhibited highly significant desirable heterosis for seed yield plant ${ }^{-1}$; one hybrid for days to maturity, one hybrid for plant height, twelve hybrids for number of branches plant ${ }^{-1}$, ten hybrids for total number of siliquae plant ${ }^{-1}$, four hybrids for 


\begin{tabular}{|c|c|c|c|c|c|c|c|c|c|c|}
\hline \multirow{2}{*}{$\begin{array}{l}\text { Sl. } \\
\text { No. }\end{array}$} & \multirow[t]{2}{*}{ Genotypes } & \multicolumn{2}{|c|}{ RI } & \multicolumn{2}{|c|}{ R II } & \multicolumn{2}{|c|}{ R III } & \multirow{2}{*}{$\begin{array}{c}\text { Total } \\
\text { flower } \\
\text { bud } \\
\text { kept }\end{array}$} & \multirow{2}{*}{$\begin{array}{l}\text { Total } \\
\text { siliquae } \\
\text { set }\end{array}$} & \multirow{2}{*}{$\begin{array}{c}\% \\
\text { Siliquae } \\
\text { set }\end{array}$} \\
\hline & & $\begin{array}{c}\text { Flower } \\
\text { bud } \\
\text { kept }\end{array}$ & $\begin{array}{c}\text { Siliquae } \\
\text { set }\end{array}$ & $\begin{array}{c}\text { Flower } \\
\text { bud } \\
\text { kept }\end{array}$ & $\begin{array}{c}\text { Siliquae } \\
\text { set }\end{array}$ & $\begin{array}{c}\text { Flower } \\
\text { bud } \\
\text { kept }\end{array}$ & $\begin{array}{c}\text { Siliquae } \\
\text { set }\end{array}$ & & & \\
\hline 1. & SKM 301×Vardan & 35 & 0 & 32 & 0 & 41 & 0 & 108 & 0 & 0 \\
\hline 2. & SKM 301×Rohini & 38 & 0 & 36 & 0 & 38 & 0 & 112 & 0 & 0 \\
\hline 3. & SKM 301×SKM 319 & 28 & 0 & 27 & 0 & 42 & 0 & 97 & 0 & 0 \\
\hline 4. & SKM 301×SKM 303 & 44 & 31 & 39 & 28 & 29 & 20 & 112 & 79 & 70.53 \\
\hline 5. & SKM 301×PusaAgrani & 38 & 29 & 29 & 21 & 40 & 30 & 107 & 80 & 74.76 \\
\hline 6. & SKM 301×PCR 7 & 36 & 26 & 32 & 23 & 35 & 25 & 103 & 74 & 71.84 \\
\hline 7. & SKM 301×Mori ‘R' 1-18 & 34 & 25 & 35 & 26 & 40 & 30 & 109 & 81 & 74.31 \\
\hline 8. & SKM 9928×Vardan & 38 & 0 & 42 & 0 & 27 & 0 & 107 & 0 & 0 \\
\hline 9. & SKM 9928×Rohini & 42 & 0 & 35 & 0 & 34 & 0 & 111 & 0 & 0 \\
\hline 10. & SKM 9928×SKM 319 & 29 & 0 & 28 & 0 & 32 & 0 & 89 & 0 & 0 \\
\hline 11. & SKM 9928×SKM 303 & 32 & 22 & 36 & 24 & 41 & 28 & 109 & 74 & 67.88 \\
\hline 12. & SKM 9928×PusaAgrani & 41 & 30 & 43 & 32 & 29 & 21 & 113 & 83 & 73.45 \\
\hline 13. & SKM 9928×PCR 7 & 46 & 32 & 34 & 24 & 27 & 19 & 107 & 75 & 70.09 \\
\hline 14. & SKM 9928×Mori 'R' 1-18 & 41 & 33 & 38 & 29 & 44 & 36 & 123 & 98 & 79.67 \\
\hline 15. & GM 1×Vardan & 28 & 0 & 31 & 0 & 38 & 0 & 97 & 0 & 0 \\
\hline 16. & GM 1×Rohini & 27 & 0 & 26 & 0 & 39 & 0 & 92 & 0 & 0 \\
\hline 17. & GM 1×SKM 319 & 38 & 0 & 28 & 0 & 29 & 0 & 95 & 0 & 0 \\
\hline 18. & GM 1×SKM 303 & 39 & 26 & 48 & 32 & 35 & 24 & 122 & 82 & 67.21 \\
\hline 19. & GM 1×PusaAgrani & 41 & 29 & 32 & 23 & 30 & 22 & 103 & 74 & 71.84 \\
\hline 20. & GM 1×PCR 7 & 44 & 30 & 44 & 30 & 42 & 29 & 130 & 89 & 68.46 \\
\hline 21. & GM 1×Mori ‘R’ 1-18 & 46 & 34 & 29 & 21 & 33 & 23 & 108 & 78 & 72.22 \\
\hline 22. & KrantixVardan & 32 & 0 & 40 & 0 & 41 & 0 & 113 & 0 & 0 \\
\hline 23. & Kranti×Rohini & 31 & 0 & 45 & 0 & 29 & 0 & 105 & 0 & 0 \\
\hline 24. & Kranti×SKM 319 & 28 & 0 & 28 & 0 & 31 & 0 & 87 & 0 & 0 \\
\hline 25. & Kranti×SKM 303 & 35 & 24 & 26 & 17 & 42 & 28 & 103 & 69 & 66.99 \\
\hline 26. & Kranti×PusaAgrani & 36 & 24 & 36 & 25 & 28 & 20 & 100 & 69 & 69.00 \\
\hline 27. & KrantixPCR 7 & 27 & 20 & 31 & 22 & 31 & 22 & 89 & 64 & 71.91 \\
\hline 28. & Kranti×Mori 'R' 1-18 & 46 & 37 & 42 & 36 & 48 & 41 & 136 & 114 & 83.82 \\
\hline 29. & GM 2×Vardan & 32 & 0 & 31 & 0 & 35 & 0 & 98 & 0 & 0 \\
\hline 30. & GM 2×Rohini & 41 & 0 & 35 & 0 & 29 & 0 & 105 & 0 & 0 \\
\hline 31. & GM 2×SKM 319 & 39 & 0 & 41 & 0 & 30 & 0 & 110 & 0 & 0 \\
\hline 32. & GM 2×SKM 303 & 38 & 25 & 28 & 20 & 32 & 22 & 98 & 67 & 68.36 \\
\hline 33. & GM 2×PusaAgrani & 40 & 28 & 32 & 22 & 35 & 25 & 107 & 75 & 70.09 \\
\hline 34. & GM 2×PCR 7 & 44 & 31 & 30 & 21 & 36 & 25 & 110 & 77 & 70.00 \\
\hline 35. & GM 2×Mori 'R’ 1-18 & 42 & 32 & 46 & 37 & 38 & 29 & 126 & 98 & 77.77 \\
\hline 36. & GDM 4 (Standard Check) & 46 & 42 & 42 & 38 & 39 & 34 & 127 & 114 & 89.76 \\
\hline
\end{tabular}




\begin{tabular}{|c|c|c|c|c|c|c|c|c|c|c|c|}
\hline $\begin{array}{l}\text { Source of } \\
\text { variation }\end{array}$ & d.f. & $\begin{array}{l}\text { Days to } \\
\text { flowering }\end{array}$ & $\begin{array}{l}\text { Days to } \\
\text { maturity }\end{array}$ & $\begin{array}{l}\text { Plant } \\
\text { height }\end{array}$ & $\begin{array}{c}\text { Total } \\
\text { no. of } \\
\text { branches } \\
\text { plant }^{-1}\end{array}$ & $\begin{array}{l}\text { Total no. } \\
\text { of siliquae } \\
\text { plant }^{-1}\end{array}$ & $\begin{array}{l}\text { Siliqua } \\
\text { length }\end{array}$ & $\begin{array}{c}\text { No.of } \\
\text { seeds } \\
\text { siliqua }^{-1}\end{array}$ & $\begin{array}{l}\text { Seed } \\
\text { yield } \\
\text { plant }^{-1}\end{array}$ & $\begin{array}{c}1000 \\
\text { seed } \\
\text { weight }\end{array}$ & $\begin{array}{c}\text { Oil } \\
\text { content }\end{array}$ \\
\hline Replications & 2 & 5.70 & 5.53 & 159.55 & 2.82 & 682.62 & 0.01 & 0.91 & 7.88 & 0.03 & 0.16 \\
\hline Treatments & 28 & $26.37^{* *}$ & $9.03^{* *}$ & $1183.18^{* *}$ & $89.10^{* *}$ & $18588.98^{* *}$ & $1.05^{* *}$ & $6.06^{* *}$ & $149.51^{* *}$ & $1.27^{* *}$ & $1.99^{* *}$ \\
\hline Parents & 8 & $26.16^{* *}$ & 5.06 & $1394.75^{* *}$ & $134.16^{* *}$ & $27191.57^{* *}$ & $0.89^{* *}$ & $5.77^{* *}$ & $222.79^{* *}$ & $1.30^{* *}$ & $3.65^{* *}$ \\
\hline Females & 4 & 3.93 & 2.23 & $408.27^{*}$ & $255.72^{* *}$ & $50620.40^{* *}$ & $1.31^{* *}$ & $7.40^{* *}$ & $384.16^{* *}$ & $2.47^{* *}$ & $5.03^{* *}$ \\
\hline Males & 3 & $18.53^{* *}$ & 5.64 & $2438.89^{* *}$ & 0.35 & 318.85 & 0.001 & 0.80 & 3.27 & $0.14^{* *}$ & $0.93^{* *}$ \\
\hline $\begin{array}{l}\text { Females vs. } \\
\text { Males }\end{array}$ & 1 & $138.02^{* *}$ & $14.67^{*}$ & $2208.27^{* *}$ & $49.32^{* *}$ & $14094.40^{* *}$ & $1.84^{* *}$ & $14.15^{* *}$ & $235.83^{* *}$ & $0.10^{*}$ & $6.29^{* *}$ \\
\hline $\begin{array}{l}\text { Parents vs. } \\
\text { Hybrids }\end{array}$ & 1 & $154.21^{* *}$ & $16.54^{*}$ & $9646.79^{* *}$ & $252.02^{* *}$ & $46103.84^{* *}$ & $0.40^{* *}$ & 0.83 & $426.74^{* *}$ & $1.76^{* *}$ & 0.002 \\
\hline Hybrids & 19 & $19.72^{* *}$ & $10.30^{* *}$ & $648.65^{* *}$ & $61.56^{* *}$ & $13518.69^{* *}$ & $1.15^{* *}$ & $6.46^{* *}$ & $104.06^{* *}$ & $1.22^{* *}$ & $1.40^{* *}$ \\
\hline Error & 56 & 2.25 & 2.73 & 153.02 & 3.04 & 912.14 & 0.039 & 1.23 & 8.90 & 0.018 & 0.14 \\
\hline
\end{tabular}

siliqua length; four hybrids for number of seeds siliqua ${ }^{-1}$, ten hybrids for 1000 seed weight and seven hybrids for oil content. None of hybrids was obtained for days to flowering which exhibited significant negative relative heterosis (Table 4, 5 and
6). The result also showed that hybrids, SKM 9928×SKM 303 and SKM 9928×Pusa Agrani which showed significant heterosis for seed yield plant ${ }^{-1}$ also possessed desirable heterotic effects for one or more important yield contributing characters like

Table 4: Estimates of heterosis in $\%$ in $F_{1}$ hybrids over mid parent, better parent and standard check GDM 4 for days to flowering, days to maturity and plant height in Indian mustard

\begin{tabular}{|c|c|c|c|c|c|c|c|c|c|c|}
\hline \multirow{2}{*}{$\begin{array}{l}\text { SI. } \\
\text { No. }\end{array}$} & \multirow[t]{2}{*}{ Hybrids } & \multicolumn{3}{|c|}{ Days to flowering } & \multicolumn{3}{|c|}{ Days to maturity } & \multicolumn{3}{|c|}{ Plant height $(\mathrm{cm})$} \\
\hline & & MP & $\mathrm{BP}$ & SC & MP & $\mathrm{BP}$ & SC & MP & $\mathrm{BP}$ & SC \\
\hline 1. & SKM 301×SKM 303 & $7.82^{* *}$ & $11.97^{* *}$ & $11.02^{* *}$ & -0.42 & 0.85 & 2.31 & $40.14^{* *}$ & $41.44^{* *}$ & $18.41^{* *}$ \\
\hline 2. & SKM 301×PusaAgrani & $5.10^{*}$ & $14.53^{* *}$ & $13.56^{* *}$ & $2.68^{*}$ & $4.60^{* *}$ & $4.90^{* *}$ & $25.95^{* *}$ & $39.55^{* *}$ & $18.99^{* *}$ \\
\hline 3. & SKM $301 \times P C R 7$ & 4.56 & $7.69^{*}$ & $6.78^{*}$ & 1.12 & 2.27 & $4.03^{* *}$ & -0.10 & $19.32^{* *}$ & 1.74 \\
\hline 4. & SKM 301×Mori R' 1-18 & $7.56^{* *}$ & $9.40^{* *}$ & $8.47^{* *}$ & -0.70 & -0.28 & $2.88^{*}$ & $26.65^{* *}$ & $26.94^{* *}$ & 7.75 \\
\hline 5. & SKM 9928×SKM 303 & $19.34^{* *}$ & $23.93^{* *}$ & $22.88^{* *}$ & $2.54^{*}$ & $3.41^{* *}$ & $4.90^{* *}$ & $27.92^{* *}$ & $29.40^{* *}$ & 8.33 \\
\hline 6. & SKM 9928×PusaAgrani & $11.37^{* *}$ & $21.37^{* *}$ & $20.34^{* *}$ & $2.55^{*}$ & $4.02^{* *}$ & $4.32^{* *}$ & $21.19^{* *}$ & $33.94^{* *}$ & $14.73^{*}$ \\
\hline 7. & SKM 9928×PCR 7 & $11.20^{* *}$ & $14.53^{* *}$ & $13.56^{* *}$ & $2.39^{*}$ & $3.12^{* *}$ & $4.90^{* *}$ & -1.23 & $17.65^{*}$ & 0.78 \\
\hline 8. & SKM 9928×Mori ‘R’ 1-18 & $9.24^{* *}$ & $11.11^{* *}$ & $10.17^{* *}$ & 0.84 & 0.84 & $4.03^{* *}$ & $27.95^{* *}$ & $28.54^{* *}$ & 9.11 \\
\hline 9. & GM 1×SKM 303 & $10.92^{* *}$ & $17.86^{* *}$ & $11.86^{* *}$ & $2.26^{*}$ & $2.84^{*}$ & $4.32^{* *}$ & $41.87^{* *}$ & $46.78^{* *}$ & $14.92^{*}$ \\
\hline 10. & GM 1×PusaAgrani & 0.00 & $11.61^{* *}$ & 5.93 & 0.00 & 1.15 & 1.44 & $21.62^{* *}$ & $41.34^{* *}$ & 10.66 \\
\hline 11. & GM $1 \times$ PCR 7 & 3.39 & $8.93^{* *}$ & 3.39 & -0.42 & 0.00 & 1.73 & 4.24 & $30.94^{* *}$ & 2.52 \\
\hline 12. & GM 1×Mori 'R' 1-18 & 2.15 & 6.25 & 0.85 & -0.28 & 0.00 & $2.59^{*}$ & $31.59^{* *}$ & $37.13^{* *}$ & 7.36 \\
\hline 13. & Kranti×SKM 303 & $19.15^{* *}$ & $28.44^{* *}$ & $18.64^{* *}$ & $4.82^{* *}$ & $5.11^{* *}$ & $6.63^{* *}$ & $18.25^{* *}$ & $22.22^{* *}$ & 2.33 \\
\hline 14. & Kranti×PusaAgrani & 0.40 & $13.76^{* *}$ & 5.08 & 1.42 & 2.30 & $2.59^{*}$ & $14.66^{* *}$ & $23.86^{* *}$ & 10.66 \\
\hline 15. & KrantixPCR 7 & $9.01^{* *}$ & $16.51^{* *}$ & $7.63^{*}$ & $2.12^{*}$ & 2.27 & $4.03^{* *}$ & $-11.19^{*}$ & 3.25 & -7.75 \\
\hline 16. & KrantixMori ‘R' 1-18 & $6.09^{*}$ & $11.93^{* *}$ & 3.39 & 0.00 & 0.56 & $2.59^{*}$ & $14.35^{*}$ & $17.35^{*}$ & -0.39 \\
\hline 17. & GM 2×SKM 303 & -0.42 & 5.31 & 0.85 & -0.42 & 0.28 & 1.73 & -1.93 & 5.79 & -11.43 \\
\hline
\end{tabular}




\begin{tabular}{|c|c|c|c|c|c|c|c|c|c|c|}
\hline \multirow{2}{*}{$\begin{array}{l}\text { SI. } \\
\text { No. }\end{array}$} & \multirow[t]{2}{*}{ Hybrids } & \multicolumn{3}{|c|}{ Days to flowering } & \multicolumn{3}{|c|}{ Days to maturity } & \multicolumn{3}{|c|}{ Plant height $(\mathrm{cm})$} \\
\hline & & MP & $\mathrm{BP}$ & SC & MP & $\mathrm{BP}$ & SC & MP & $\mathrm{BP}$ & SC \\
\hline 18. & GM 2×PusaAgrani & -1.20 & $9.73^{* *}$ & 5.08 & 0.99 & 2.30 & $2.59^{*}$ & -7.63 & -4.40 & -7.36 \\
\hline 19. & GM 2×PCR 7 & 4.64 & $9.73^{* *}$ & 5.08 & -1.41 & -0.85 & 0.86 & -7.11 & 3.20 & 0.00 \\
\hline 20. & GM 2×Mori 'R' 1-18 & 0.85 & 4.42 & 0.00 & $-2.66^{*}$ & $-2.52^{*}$ & 0.29 & 9.17 & $16.89^{*}$ & -0.78 \\
\hline \multicolumn{2}{|c|}{ SEm \pm} & 1.06 & 1.22 & 1.22 & 1.17 & 1.35 & 1.35 & 8.75 & 10.10 & 10.10 \\
\hline \multicolumn{2}{|c|}{ Range } & $\begin{array}{l}-1.20 \text { to } \\
+19.34\end{array}$ & $\begin{array}{l}+4.42 \text { to } \\
+28.44\end{array}$ & $\begin{array}{l}0.00 \text { to } \\
+22.88\end{array}$ & $\begin{array}{c}-2.66 \text { to } \\
+4.82\end{array}$ & $\begin{array}{c}-2.52 \text { to } \\
+5.11\end{array}$ & $\begin{array}{c}0.29 \text { to } \\
6.63\end{array}$ & $\begin{array}{l}-11.19 \text { to } \\
+41.87\end{array}$ & $\begin{array}{l}-4.40 \text { to } \\
+46.78\end{array}$ & $\begin{array}{c}-11.43 \text { to } \\
+18.99\end{array}$ \\
\hline \multicolumn{2}{|c|}{ Significant Heterosis } & 11 & 17 & 11 & 8 & 7 & 14 & 13 & 16 & 4 \\
\hline \multicolumn{2}{|c|}{ Number of +ve significant } & 11 & 17 & 11 & 7 & 6 & 14 & 12 & 16 & 4 \\
\hline \multicolumn{2}{|c|}{ Number of -ve significant } & 0 & 0 & 0 & 1 & 1 & 0 & 1 & 0 & 0 \\
\hline
\end{tabular}

$*: p \leq 0.05, * *: p \leq 0.01$

Table 5: Estimates of heterosis in \% in $\mathrm{F}_{1}$ hybrids over mid parent, better parent and standard check GDM 4 for total number of branches plant ${ }^{-1}$, total number of siliquae plant ${ }^{-1}$, siliqua length and numbers of seeds siliqua ${ }^{-1}$ in Indian mustard

\begin{tabular}{|c|c|c|c|c|c|c|c|c|c|c|}
\hline \multirow[t]{2}{*}{$\begin{array}{l}\text { SI. } \\
\text { No. }\end{array}$} & \multirow[t]{2}{*}{ Hybrids } & \multicolumn{3}{|c|}{$\begin{array}{c}\text { Total number of branches } \\
\text { plant }^{-1}\end{array}$} & \multicolumn{3}{|c|}{$\begin{array}{l}\text { Total number of siliquae } \\
\text { plant }^{-1}\end{array}$} & \multicolumn{3}{|c|}{$\begin{array}{l}\text { Siliqua length } \\
(\mathrm{cm})\end{array}$} \\
\hline & & MP & $\mathrm{BP}$ & SC & MP & $\mathrm{BP}$ & SC & MP & $\mathrm{BP}$ & SC \\
\hline 1. & SKM 301×SKM 303 & $-14.91^{* *}$ & $-31.53^{* *}$ & $-30.38^{* *}$ & $-17.66^{* *}$ & $-31.50^{* *}$ & $-28.16^{* *}$ & 5.42 & $-10.00^{* *}$ & -4.83 \\
\hline 2. & SKM 301×PusaAgrani & $-21.73^{* *}$ & $-38.12^{* *}$ & $-37.08^{* *}$ & $-18.35^{* *}$ & $-34.21^{* *}$ & $-31.01^{* *}$ & $-10.30^{* *}$ & $-23.09^{* *}$ & $-18.67^{* *}$ \\
\hline 3. & SKM 301×PCR 7 & 10.22 & $-12.47^{*}$ & $-11.00^{*}$ & 7.42 & $-13.06^{*}$ & -8.82 & $-7.43^{*}$ & $-20.74^{* *}$ & $-16.19^{* *}$ \\
\hline 4. & SKM 301×Mori R' 1-18 & $11.96^{*}$ & $-10.82^{*}$ & -9.33 & 8.63 & $-11.41^{*}$ & -7.09 & 2.53 & $-12.47^{* *}$ & $-7.44^{*}$ \\
\hline 5. & SKM 9928×SKM 303 & $25.75^{* *}$ & 13.13 & $-29.90^{* *}$ & $17.00^{*}$ & 7.28 & $-25.31^{* *}$ & $51.71^{* *}$ & $50.79^{* *}$ & $12.79^{* *}$ \\
\hline 6. & SKM 9928×PusaAgrani & $93.83^{* *}$ & $78.14^{* *}$ & 5.26 & $77.55^{* *}$ & $69.12^{* *}$ & 8.46 & $45.33^{* *}$ & $43.70^{* *}$ & $8.62^{*}$ \\
\hline 7. & SKM 9928×PCR 7 & $81.18^{* *}$ & $65.60^{* *}$ & -0.96 & $63.99^{* *}$ & $55.36^{* *}$ & 0.79 & 0.44 & -0.52 & $-25.07^{* *}$ \\
\hline 8. & SKM 9928×Mori ‘R’ 1-18 & $79.52^{* *}$ & $63.49^{* *}$ & -1.44 & $63.86^{* *}$ & $53.79^{* *}$ & 1.78 & $26.60^{* *}$ & $25.83^{* *}$ & -5.87 \\
\hline 9. & GM 1×SKM 303 & 13.12 & -3.47 & $-40.19^{* *}$ & 9.47 & -4.93 & $-33.81^{* *}$ & 3.66 & 3.66 & $-22.45^{* *}$ \\
\hline 10. & GM 1×PusaAgrani & $21.86^{* *}$ & 6.07 & $-37.32^{* *}$ & 10.86 & -0.22 & $-36.01^{* *}$ & -2.26 & -2.76 & $-26.50^{* *}$ \\
\hline 11. & GM 1×PCR 7 & $27.94^{* *}$ & 10.80 & $-33.73^{* *}$ & $24.13^{* *}$ & 11.15 & $-27.89^{* *}$ & 5.22 & 4.85 & $-21.02^{* *}$ \\
\hline 12. & GM 1×Mori ‘R’ 1-18 & $45.75^{* *}$ & $25.79^{* *}$ & $-24.16^{* *}$ & $35.76^{* *}$ & $20.51^{*}$ & $-20.25^{* *}$ & -1.75 & -1.75 & $-26.50^{* *}$ \\
\hline 13. & Kranti×SKM 303 & -6.80 & $-27.27^{* *}$ & $-19.62^{* *}$ & -5.88 & $-24.61^{* *}$ & $-12.80^{*}$ & 0.16 & $-7.66^{*}$ & $-18.15^{* *}$ \\
\hline 14. & KrantixPusa Agrani & $-19.89^{* *}$ & $-38.53^{* *}$ & $-32.06^{* *}$ & $-19.14^{* *}$ & $-37.15^{* *}$ & $-27.31^{* *}$ & -2.23 & $-9.43^{*}$ & $-19.71^{* *}$ \\
\hline 15. & Kranti×PCR 7 & -10.11 & $-30.74^{* *}$ & $-23.44^{* *}$ & -8.03 & $-28.22^{* *}$ & $-16.99^{* *}$ & 1.91 & -5.74 & $-16.45^{* *}$ \\
\hline 16. & Kranti×Mori ‘R’ 1-18 & $23.53^{* *}$ & -4.55 & 5.50 & $25.69^{* *}$ & -1.20 & $14.27^{*}$ & -2.72 & $-10.31^{* *}$ & $-20.50^{* *}$ \\
\hline 17. & GM 2×SKM 303 & 3.59 & -10.81 & $-44.74^{* *}$ & 5.66 & -5.15 & $-33.96^{* *}$ & $-18.65^{* *}$ & $-23.14^{* *}$ & $-35.38^{* *}$ \\
\hline 18. & GM 2×PusaAgrani & $40.09^{* *}$ & $23.08^{*}$ & $-27.27^{* *}$ & $31.66^{* *}$ & $22.66^{*}$ & $-21.33^{* *}$ & $14.15^{* *}$ & $8.39^{*}$ & $-8.88^{* *}$ \\
\hline 19. & GM 2×PCR 7 & $30.43^{* *}$ & 14.00 & $-31.82^{* *}$ & $26.03^{* *}$ & 16.80 & $-24.23^{* *}$ & -6.47 & $-11.34^{* *}$ & $-25.46^{* *}$ \\
\hline 20. & GM 2×Mori 'R' 1-18 & $94.08^{* *}$ & $69.05^{* *}$ & 1.91 & $79.50^{* *}$ & $64.84^{* *}$ & 9.09 & $-8.79^{*}$ & $-13.82^{* *}$ & $-27.55^{* *}$ \\
\hline \multicolumn{2}{|l|}{ SEm+ } & 1.23 & 1.42 & 1.42 & 21.36 & 24.66 & 24.66 & 0.14 & 0.16 & 0.16 \\
\hline \multicolumn{2}{|c|}{ Significant Heterosis } & 15 & 13 & 14 & 13 & 13 & 14 & 8 & 14 & 18 \\
\hline \multicolumn{2}{|c|}{ Number of +ve significant } & 12 & 6 & 0 & 10 & 6 & 1 & 4 & 4 & 2 \\
\hline \multicolumn{2}{|c|}{$\begin{array}{l}\text { Number of -ve significant } \\
*: p \leq 0.05, * *: p \leq 0.01\end{array}$} & 3 & 7 & 14 & 3 & 7 & 13 & 4 & 10 & 16 \\
\hline
\end{tabular}




\begin{tabular}{|c|c|c|c|c|}
\hline \multirow{2}{*}{$\begin{array}{l}\text { SI. } \\
\text { No. }\end{array}$} & \multirow[t]{2}{*}{ Hybrids } & \multicolumn{3}{|c|}{ Number of seeds siliqua $^{-1}$} \\
\hline & & MP & $\mathrm{BP}$ & SC \\
\hline 1. & SKM 301×SKM 303 & 7.98 & -6.12 & 2.22 \\
\hline 2. & SKM 301×PusaAgrani & $-11.63^{*}$ & $-22.45^{* *}$ & $-15.56^{*}$ \\
\hline 3. & SKM 301×PCR 7 & $-17.12^{* *}$ & $-24.90^{* *}$ & $-18.22^{* *}$ \\
\hline 4. & SKM 301×Mori R' 1-18 & $11.72^{*}$ & -0.82 & 8.00 \\
\hline 5. & SKM 9928×SKM 303 & $33.88^{* *}$ & $31.38^{* *}$ & 9.78 \\
\hline 6. & SKM 9928×PusaAgrani & $21.18^{* *}$ & $20.21^{* *}$ & 0.44 \\
\hline 7. & SKM 9928×PCR 7 & -1.29 & -4.02 & $-15.11^{*}$ \\
\hline 8. & SKM 9928×Mori ‘R’ 1-18 & $22.75^{* *}$ & $22.11^{* *}$ & 3.11 \\
\hline 9. & GM 1×SKM 303 & 1.62 & -0.53 & $-16.44^{* *}$ \\
\hline 10. & GM 1×PusaAgrani & 8.02 & 6.88 & -10.22 \\
\hline 11. & GM $1 \times$ PCR 7 & 1.03 & -1.51 & $-12.89^{*}$ \\
\hline 12. & GM 1×Mori 'R’ 1-18 & -3.96 & -4.21 & $-19.11^{* *}$ \\
\hline 13. & Kranti×SKM 303 & 0.25 & -8.26 & -11.11 \\
\hline 14. & KrantixPusa Agrani & 4.22 & -3.67 & -6.67 \\
\hline 15. & KrantixPCR 7 & -6.47 & -10.55 & $-13.33^{*}$ \\
\hline 16. & KrantixMori 'R’ 1-18 & -3.92 & -10.09 & $-12.89^{*}$ \\
\hline 17. & GM 2×SKM 303 & $-16.24^{* *}$ & $-22.54^{* *}$ & $-26.67^{* *}$ \\
\hline 18. & GM 2×PusaAgrani & 11.06 & 3.76 & -1.78 \\
\hline 19. & GM 2×PCR 7 & -6.80 & -9.86 & $-14.67^{*}$ \\
\hline 20. & GM 2×Mori 'R' 1-18 & -5.21 & -10.33 & $-15.11^{*}$ \\
\hline SEm & & 0.78 & 0.91 & 0.91 \\
\hline Sign & ficant Heterosis & 7 & 6 & 11 \\
\hline Num & ber of +ve significant & 4 & 3 & 0 \\
\hline Num & ber of -ve significant & 3 & 3 & 11 \\
\hline
\end{tabular}

$*: p \leq 0.05, * *: p \leq 0.01$ number of branches plant ${ }^{-1}$, total number of siliquae plant ${ }^{-1}$, siliqua length, number of seeds siliqua ${ }^{-1}, 1000$-seed weight and oil content.The similar results were also reported by Arher et al. (2009), Gami et al. (2011) and Synrem et al. (2015).

The highly significant heterobeltiosis for seed yield plant ${ }^{-1}$ was recorded by the eight hybrids i.e., SKM 9928×SKM 303 (46.59\%), SKM 9928×Pusa Agrani (115.42\%), SKM 9928×PCR 7 (57.87\%), SKM 9928×Mori 'R' 1-18 (83.85\%), GM 1×Pusa Agrani (43.83\%), GM 1×PCR 7 (30.30\%), GM 1×Mori 'R' 1-18 (35.31\%) and GM 2×Mori 'R' 1-18 (46.54\%). Several hybrids registered significant heterobeltiosis in desirable direction for various characters under study viz., days to maturity (one hybrid), total number of branches plant ${ }^{-1}$ (five hybrids), total number of siliquaeplant ${ }^{-1}$ (six hybrids), siliqua length (four hybrids), number of seeds siliqua ${ }^{-1}$ (three hybrids), 1000 seed weight (eight hybrids) and oil content(five hybrids). None of hybrids exhibited significant negative heterobeltiosis for days to flowering and plant height. The best two hybrids, SKM $9928 \times$ Pusa Agrani (115.42\%) and SKM 9928×PCR 7(57.87\%) exhibited significant heterobeltiosis for seed yield plant ${ }^{1}$ also manifested significant heterobeltiosis for one or more important yield characters like number of branches plant ${ }^{-1}$, total number of siliquae plant ${ }^{-1}, 1000$ seed weight and oil content (Table 4, 5 and 6). Significant heterobeltiosis for seed yield plant ${ }^{-1}, 1000$ seed weightand oil content was also reported by Chodhary et al (2020).

The variety, GDM 4 released for general cultivation in Gujarat, therefore used as standard variety in order to obtain information regarding superiority of new hybrids over best cultivated variety. None of the hybrids however manifested significant desirable standard heterosis for days to flowering, days to maturity, plant height, number of branches plant ${ }^{-1}$ and number of seeds siliqua ${ }^{-1}$. In this study, only one hybrid KrantixMori ' $R$ ' 1-18 showed positive and significant heterosis

Table 6: Estimates of heterosis in \% in $F_{1}$ hybrids over mid parent, better parent and standard check GDM 4 for seed yield plant $^{-1}, 1000$ seed weight and oil content in Indian mustard

\begin{tabular}{|c|c|c|c|c|c|c|c|c|c|c|}
\hline \multirow{2}{*}{$\begin{array}{l}\text { SI. } \\
\text { No. }\end{array}$} & \multirow[t]{2}{*}{ Hybrids } & \multicolumn{3}{|c|}{ Seed yield plant ${ }^{-1}(\mathrm{~g})$} & \multicolumn{3}{|c|}{1000 seed weight (g) } & \multicolumn{3}{|c|}{ Oil content (\%) } \\
\hline & & MP & $\mathrm{BP}$ & SC & MP & $\mathrm{BP}$ & SC & MP & $\mathrm{BP}$ & SC \\
\hline 1. & SKM 301×SKM 303 & 8.00 & -15.23 & -14.91 & $20.91^{* *}$ & $12.94^{* *}$ & $6.86^{* *}$ & 1.44 & 0.57 & -1.36 \\
\hline 2. & SKM 301×Pusa Agrani & $-38.67^{* *}$ & $-53.96^{* *}$ & $-53.79^{* *}$ & $-13.43^{* *}$ & $-15.40^{* *}$ & $-27.20^{* *}$ & $2.71^{* *}$ & $2.53^{* *}$ & -1.16 \\
\hline 3. & SKM 301×PCR 7 & -4.73 & $-25.23^{* *}$ & $-24.95^{* *}$ & $5.49^{* *}$ & 0.13 & $-8.46^{* *}$ & $2.84^{* *}$ & $2.34^{* *}$ & -1.34 \\
\hline 4. & SKM 301×Mori R' 1-18 & 11.91 & -12.90 & -12.57 & $-5.64^{* *}$ & $-8.69^{* *}$ & $-19.81^{* *}$ & -0.78 & $-1.83^{*}$ & $-3.32^{* *}$ \\
\hline 5. & SKM 9928×SKM 303 & $63.31^{* *}$ & $46.59^{* *}$ & $-16.15^{*}$ & 3.27 & -2.19 & $-7.45^{* *}$ & $3.26^{* *}$ & $2.06^{*}$ & 0.10 \\
\hline 6. & SKM 9928×Pusa Agrani & $126.29^{* *}$ & $115.42^{* *}$ & 8.41 & $7.83^{* *}$ & $6.94^{* *}$ & $-7.98^{* *}$ & $3.01^{* *}$ & $2.87^{* *}$ & -1.19 \\
\hline 7. & SKM 9928×PCR 7 & $75.85^{* *}$ & $57.87^{* *}$ & -9.72 & $10.51^{* *}$ & $6.40^{* *}$ & -2.72 & $2.07^{* *}$ & $1.89^{*}$ & $-2.39^{* *}$ \\
\hline 8. & SKM 9928×Mori ‘R’ 1-18 & $102.68^{* *}$ & $83.85^{* *}$ & 2.72 & 1.44 & -0.40 & $-12.54^{* *}$ & $1.72^{*}$ & 0.33 & -1.19 \\
\hline 9. & GM 1×SKM 303 & -0.95 & -18.33 & $-53.29^{* *}$ & $-9.91^{* *}$ & $-18.19^{* *}$ & $-22.59^{* *}$ & 0.30 & -0.96 & -0.36 \\
\hline 10. & GM 1×Pusa Agrani & $65.54^{* *}$ & $43.83^{* *}$ & $-27.62^{* *}$ & $41.76^{* *}$ & $34.50^{* *}$ & $15.73^{* *}$ & $-3.40^{* *}$ & $-5.59^{* *}$ & $-5.01^{* *}$ \\
\hline 11. & GM $1 \times$ PCR 7 & $58.01^{* *}$ & $30.30^{*}$ & $-25.49^{* *}$ & $27.56^{* *}$ & $17.66^{* *}$ & $7.57^{* *}$ & $-2.22^{* *}$ & $-4.72^{* *}$ & $-4.14^{* *}$ \\
\hline
\end{tabular}




\begin{tabular}{|c|c|c|c|c|c|c|c|c|c|c|}
\hline \multirow{2}{*}{$\begin{array}{l}\text { Sl. } \\
\text { No. }\end{array}$} & \multirow[t]{2}{*}{ Hybrids } & \multicolumn{3}{|c|}{ Seed yield plant ${ }^{-1}(\mathrm{~g})$} & \multicolumn{3}{|c|}{1000 seed weight $(\mathrm{g})$} & \multicolumn{3}{|c|}{ Oil content (\%) } \\
\hline & & MP & $\mathrm{BP}$ & SC & MP & $\mathrm{BP}$ & SC & MP & $\mathrm{BP}$ & SC \\
\hline 12. & GM 1×Mori 'R' 1-18 & $62.58^{* *}$ & $35.31^{*}$ & $-24.40^{* *}$ & $28.48^{* *}$ & $20.74^{* *}$ & $6.03^{* *}$ & $-1.56^{*}$ & $-2.61^{* *}$ & $-2.01^{*}$ \\
\hline 13. & Kranti×SKM 303 & -9.02 & $-32.79^{* *}$ & $-19.49^{*}$ & -2.73 & $-5.48^{* *}$ & $-5.20^{*}$ & $-2.35^{* *}$ & $-3.87^{* *}$ & $-2.68^{* *}$ \\
\hline 14. & Kranti×Pusa Agrani & -3.84 & $-31.72^{* *}$ & $-18.21^{*}$ & $18.31^{* *}$ & $9.91^{* *}$ & $10.23^{* *}$ & -0.59 & $-3.13^{* *}$ & $-1.94^{*}$ \\
\hline 15. & KrantixPCR 7 & -8.27 & $-32.24^{* *}$ & $-18.83^{*}$ & $7.83^{* *}$ & 3.07 & 3.37 & $1.45^{*}$ & -1.45 & -0.23 \\
\hline 16. & Kranti×Mori 'R' 1-18 & $34.18^{* *}$ & -1.62 & $17.85^{*}$ & $15.62^{* *}$ & $8.43^{* *}$ & $8.75^{* *}$ & $-4.32^{* *}$ & $-5.63^{* *}$ & $-4.46^{* *}$ \\
\hline 17. & GM 2×SKM 303 & -15.19 & -20.90 & $-47.71^{* *}$ & $-6.61^{* *}$ & $-15.38^{* *}$ & -1.42 & -0.84 & $-3.66^{* *}$ & 0.19 \\
\hline 18. & GM 2×Pusa Agrani & $37.30^{* *}$ & 20.92 & $-20.07^{*}$ & $-7.45^{* *}$ & $-19.54^{* *}$ & $-6.27^{* *}$ & 1.35 & $-2.51^{* *}$ & 1.38 \\
\hline 19. & GM 2×PCR 7 & 15.55 & 7.76 & $-28.77^{* *}$ & $-3.81^{*}$ & $-14.16^{* *}$ & 0.00 & -0.92 & $-4.98^{* *}$ & -1.19 \\
\hline 20. & GM 2×Mori ‘R’ 1-18 & $58.84^{* *}$ & $46.54^{* *}$ & -3.13 & $-5.93^{* *}$ & $-17.51^{* *}$ & -3.90 & 0.69 & $-1.97^{*}$ & $1.94^{*}$ \\
\hline \multicolumn{2}{|c|}{ SEm \pm} & 2.11 & 2.44 & 2.44 & 0.10 & 0.11 & 0.11 & 0.26 & 0.30 & 0.30 \\
\hline \multicolumn{2}{|c|}{ Range } & $\begin{array}{c}-38.67 \\
\text { to } \\
+126.29\end{array}$ & $\begin{array}{c}-53.96 \\
\text { to } \\
+115.42\end{array}$ & $\begin{array}{c}-53.79 \\
\text { to } \\
+17.85\end{array}$ & $\begin{array}{c}-13.43 \\
\text { to } \\
+41.76\end{array}$ & $\begin{array}{c}-19.54 \\
\text { to } \\
+34.50\end{array}$ & $\begin{array}{c}-27.20 \\
\text { to } \\
+15.73\end{array}$ & $\begin{array}{l}-4.32 \\
\text { to } \\
+3.26\end{array}$ & $\begin{array}{c}-5.63 \\
\text { to } \\
+2.87\end{array}$ & $\begin{array}{c}-5.01 \\
\text { to } \\
+1.94\end{array}$ \\
\hline \multicolumn{2}{|c|}{ Significant Heterosis } & 11 & 13 & 14 & 17 & 16 & 15 & 12 & 16 & 9 \\
\hline \multicolumn{2}{|c|}{ Number of +ve significant } & 10 & 8 & 1 & 10 & 8 & 6 & 7 & 5 & 1 \\
\hline \multicolumn{2}{|c|}{ Number of -ve significant } & 1 & 5 & 13 & 7 & 8 & 9 & 5 & 11 & 8 \\
\hline
\end{tabular}

$*$ : $p \leq 0.05, * *: p \leq 0.01$

over standard check GDM 4 for seed yield plant $^{-1}$. The top three hybrids which evinced promising standard heterosis were GM 1×Pusa Agrani, KrantixPusa Agrani and KrantixMori ' $R$ ' 1-18 for 1000 seed weight and for oil content, the superior hybrid was GM 2×Mori ' $R$ ' 1-18. The best hybrids for siliqua length over the standard check GDM 4 were SKM 9928×SKM 303and SKM 9928xPusaAgrani. The superior hybrid over standard check GDM 4 for total number of siliquae plant ${ }^{-1}$ was KrantixMori ' $R$ ' 1-18 (Table 4, 5 and 6). The present findings were in close agreement with the findings of Patel et al. (2010), Verma et al. (2011), Kumar et al. (2014b) and Synrem et al. (2015).

\section{Conclusion}

Hybrid KrantixMori ' $R$ ' 1-18 was identified as best heterotic combination for total number of siliquae plant ${ }^{-1}$, seed yield plant $^{-1}$ and 1000 seed weight. Hybrids, SKM 301×SKM 303, SKM 9928xPusa Agrani and KrantixMori 'R' 1-18 had good genetic architecture and needed large scale testing to develop a superior hybrid with high and stable seed yield in Brassica juncea $\mathrm{L}$.

\section{References}

Alexander, M.P., 1969. Differential staining of aborted and non-aborted pollen. Stain Technology 44, 117-122.

Anonymous, 2020. Five-year oilseeds and commercial crops 2019-20, Directorate of economics and statistics, department of agriculture, cooperation and farmers welfare, Ministry of Agriculture \& Farmers Welfare, Govt. of India. Available at https://eands.dacnet.nic.in/ APY_96_To_06.htm. Accessed on 31 July, 2021

Arher, C.D., Shelke, L.T., Chinchane, V.N., Borgaonkar, S.B., Gaikwad, A.R., 2009. Heterosis for yield and yield components in Indian mustard [Brassica juncea (L.) Czern and Coss]. International Journal of Plant Sciences (Muzaffarnagar) 4(1), 30-32.

Azizia, S., 2011. Combining ability analysis for yield component parameters in winter rapeseed genotypes (Brassica napus L.). Journal of Oilseed Brassica 2, 21-28.

Banga, S.S., Deol, J.S., Banga, S.K., 2003. Alloplasmic male sterile Brassica juncea with Enarthrocarpus lyratus cytoplasm and the introgression of gene (s) for fertility restoration from cytoplasm donor species. Theoretical and Applied Genetics 106, 1390-1395.

Bhat, S.R., Kumar, P., Prakash, S., 2008. An improved cytoplasmic male sterile (Diplotaxis berthautii) Brassica juncea: identification of restorer and molecular characterization. Euphytica 159, 145-152.

Bhat, S.R., Vijayan, P., Ashutosh, Dwivedi, K.K., Prakash, S., 2006. Diplotaxis erucoides-induced cytoplasmic male sterility in Brassica juncea is rescued by the Moricandia arvensis restorer: genetic and molecular analyses. Plant Breeding 125, 150-155.

Chamola, R., Balyan H.S., Bhat S.R., 2013. Effect of alien cytoplasmand fertility restorer genes on agronomic and physiological traits of Brassica juncea (L.) Czern \& Coss. Plant Breeding 132, 681-687. 
Chaurasiya, J.P., Singh, M., Yadav, R.K., Singh, L., Yadav, H.C., 2018. Genetic analysis for estimates components of genetic variance in Indian mustard (Brassica juncea (L.) Czern \& Coss).The Pharma Innovation Journal 7(2), 104-107.

Choudhary, R.R., Sheoran, R.K., Avtar, R., Kumar, D., Samita, 2020. Heterosis studies based upon Mori CMS system in Brassica juncea L. Journal of Oilseed Research 11(2), 116-120.

Diepenbrock, W., 2000. Yield analysis of winter oilseed rape (B. napus L.): A review. Field Crop Research 67, 35-49.

Fonesca, S., Patterson, P., 1968. Hybrid vigour in a seven parent diallel crosses in common winter wheat. Crop Science 8, 85-88.

Gami, R.A., Thakkar, D.A., Patel, M.P., Parmar, H.D., Patel, P.S., 2011. Heterosis for seed yield and its components in Indian mustard [Brassica juncea (L.) Czern \& Coss]. Journal of Oilseeds Research 28(1), 60-62.

Gupta, S.K., 2016. Biology and breeding of crucifers. Boca Raton FL: CRC Press.

Kaur, G., Banga, S.K., Gogna, K.P.S., Joshi, S., Banga, S.S., 2004. Moricandia arvensis cytoplasm based system of cytoplasmic male sterility in Brassica juncea: reappraisal of fertility restoration and agronomic potential. Euphytica 138(3), 271-276.

Kirti, P.B., Prakash, S., Gaikwad, K., Bhat, S.R., Dinesh kumar, V., Chopra, V.L., 1998. Chloroplast substitution overcomes leaf chlorosis in a Moricandia arvensis-based cytoplasmic male sterile Brassica juncea. Theoretical and Applied Genetics 97, 1179-1182.

Kumar, A., Yadav, N.P., Kumar, K., 2014a. Study for restoration ability in cytoplasmic male sterile system in Indian mustard [Brassica juncea (L.) Czern \& Coss]. Electronic Journal of Plant Breeding 5(2), 280-283.

Kumar, B., Pandey, A., Singh., S.K., 2014b. Combining ability and economic heterosis for yield and oil quality traits in Indian mustard (Brassica juncea L. Czern \& Coss). Electronic Journal of Plant Breeding 5(2), 203-207.

Kumari, V., Jambhulka, S., Chaudhary, H.K., Sharma, B.K., Sood, P., Guleria, S.K., 2019. Phenotypic stability for seed yield and related traits in Trombaymustard genotypes under North Western Himalayas. Journal of Oilseed Brassica 10, 33-37.

Malik, M., Vyas, P., Rangaswamy, N.S., Shivanna, K.R., 1999. Development of two new cytoplasmic male sterile lines of Brassica juncea through wide hybridization. Plant Breeding 118, 75-78.

Meena, J., Harsha, Pant, U., Bhajan, R., 2015. Heterosis analysis for yield and yield attributing traits in Indian mustard (Brassica juncea (L.) Czern \& Coss). Electronic Journal of Plant Breeding 6(4), 1103-1107.

Meredith, W.R., Bridge, R.R., 1972. Heterosis and gene action in cotton Gossypium hirsutum. Crop Science12, 304-310.
Nagaharu, U., 1935. Genome analysis in Brassica with special reference to the experimental formation of Brassica napus and peculiar mode of fertilization. Japanese Journal of Botany 7, 389-452.

Panse, V.G., Sukhatme, P.V., 1967. Statistical method for agricultural workers (2 ${ }^{\text {nd }}$ Ed. ICAR, New Delhi: Pp. 381.

Park, K.Y., Kwon, D.Y., Lee, K.W., Park, S., 2018. Korean functional foods: composition, Processing and Health Benefits. CRC Press.

Patel, C.G., Parmar, M.B., Patel, K.R., Patel, K.M., 2010. Exploitation of heterosis breeding in Indian mustard,Brassica juncea (L.) Czern \& Coss. Journal of Oilseeds Research 27(1), 47-48.

Prakash, S., Ahuja, I., Bhatt, S.R., Kirti, P.B., Chopra, V.L., 2001. Expression of male sterility in alloplasmic Brassica juncea with Erucastrum canariense cytoplasm and development of a system for fertility restoration. Plant Breeding 120, 479-482.

Prakash, S., Kirti, P.B., 1997. Synthesis of allo-plasmic male sterile systems and introgression of fertility restoration genes in mustard. In: CYMMYT International Symposium. August 17-22, Mexico, 132-133.

Prakash, S., Kirti, P.B., Bhat, S.R., Gaikwad, K., Kumar, V.D., Chopra, V.L., 1998. A Moricandia arvensis based cytoplasmic male sterility and fertility restoration system in Brassica juncea. Theoretical and Applied Genetics 97, 488-492.

Rao, G.U., Shivanna, K.R., 1996. Development of a new alloplasmic CMS Brassica napus in the cytoplasmic background of Diplotaxis siifolia. Cruciferae Newsletter 18, 68-69.

Shrimali, T.M., Chauhan, R.M., Gami, R.A., Patel, P.T., 2016. Diallel analysis in Indian mustard (Brassica juncea L. Czern \& Coss.). Electronic Journal of Plant Breeding 7(4), 919-924.

Singh, A., Avtar, R., Singh, D., Sangwan, O., Thakral, N.K., Malik, V.S., Goyat, B., Dalal, U., 2013. Combining ability analysis for seed yield and component traits in Indian mustard [Brassica juncea (L.) Czern \& Coss.]. Research in Plant Biology 3(2), 26-31.

Singh, D., Mehta, R., 1954. Studies on breeding brown sarson. I. Comparison of F1's and their parents. Indian Journal of Genetics and Plant Breeding 14, 74-77.

Synrem, G.J., Rangare, N.R., Choudhari, K.A., Kumar S., Myrthong, I., 2015. Combining ability analysis for seed yield and component traits in Indian mustard [Brassica juncea (L.) Czern \& Coss.]. Electronic Journal of Plant Breeding 6(2), 445-453.

Tiwari, P.N., Gambier, P.N., Rajan, T.S., 1974. Rapid and nondestructive determination of seed oil by Pulsed Nuclear Magnetic Resonance Technique. Journal of American Chemistry Society 51, 104-109. 
Turner, J.H., 1953. A study of heterosis in upland cotton, combining ability and inbreeding effects. Agronomy Journal 43, 478-490.

Vaghela, P.O., Thakkar, D.A., Bhadauria, H.S., Sutariya, D.A., Parmar, S.K., Prajapati, D.V., 2011. Heterosis and combining ability for yield and its component traits in Indian mustard (Brassica juncea L.). Journal of Oilseed Brassica 2(1), 39-43.

Vaughan, J.G., 1977. Multidisciplinary study of the taxonomy and origin of Brassica crops. Bio-Science 27(1), 35-40.

Verma, O.P., Yadav, R., Kumar, K., Singh, R., Maurya, K.N.,
Ranjana, 2011. Combining ability and heterosis for seed yield and its components in Indian mustard (Brassica juncea). Plant Archive 11, 863-865.

Yadava, D.K., Singh, N., Vasudev, S., Singh, S., Giri, S.C., Dwivedi, V.K., Prabhu, K.V., 2012. Combining ability and heterobeltiosis for yield and yield contributing traits in Indian mustard (Brassica juncea). Indian Journal of Agricultural Sciences 82(7), 563-567. 